\title{
Novas Direçóes na Filosofia da Mente
}

\author{
Gabriel Jucá de Hollanda ${ }^{I}$
}

\begin{abstract}
RESUMO: As críticas a teorias naturalistas/fisicalistas na filosofia da mente têm focado problemas conceituais fundamentados em qualia e experimentos de pensamento. Cabe questionar a validade de tais críticas, se o alvo das mesmas satisfaz as exigências de uma explicação científica e se as objeçôes envolvem asserções aparentemente ad hoc. Os filósofos da mente Tyler Burge e Alva Noë, sem fazer uso de tais recursos teóricos, propóem novas maneiras de questionar a neurociência atual. Suas perspectivas chamam atenção pelo foco em problemas empíricos e ainda assim revelam lacunas surpreendentes, no que fisicalistas tendem a considerar a ciência mais avançada da mente.
\end{abstract}

PALAVRAS-CHAVE: Mente. Neurociência. Percepçăo. Visão. Explicaçăo.

A neurociência cognitiva é vista em muitos círculos científicos e filosóficos como uma ciência relativamente madura e apta a explicar os fenômenos da consciência humana através da detecção de correlatos neurais da consciência. Essa perspectiva tem sido criticada por décadas, na filosofia, como um reducionismo que distorce os dados da subjetividade. Tais críticas dependem de conceitos como qualia e experiência fenomenal, termos de uso puramente filosófico que são articulados por meio de experimentos de pensamento. Alega-se que tais termos, independentemente da engenhosidade de seu uso, não têm um papel em contribuiçôes positivas. Dito de outra forma, não é claro que termos como qualia e experiência fenomenal são indispensáveis para teorias candidatas a explicar os dados.

Nesse contexto, as muito recentes teorias da percepção dos filósofos Tyler Burge e Alva Noë oferecem algo inovador. A ortodoxia neurocientífica é criticada a partir de termos reconhecidos na atividade científica, ao mesmo tempo em que novos caminhos são sugeridos e intensamente articulados com dados empíricos. A repercussão desses trabalhos conduz naturalmente a uma avaliação de sua alegada superioridade em relação à neurociência cognitiva.

\footnotetext{
1 Doutor em filosofia (PUC-Rio, 2011) e professor na PUC-Rio, lecionando lógica e filosofia da ciência. E-mail: gabrieljuca@gmail.com. O autor gostaria de agradecer aos Professores Oswaldo Chateaubriand e Gustavo Leal-Toledo, assim como a Cecília Jucá de Hollanda.
} 
A neurociência cognitiva é a disciplina que estuda o cérebro à luz de problemas propostos por cientistas cognitivos, problemas esses que dizem respeito às tarefas que um organismo inteligente deve realizar. A premissa fundamental toma a mente como um conjunto de dispositivos de processamento de informaçóes (BROOK; MANDIK, 2004). O alvorecer da neurociência cognitiva nos anos 1980 tornou-se possível graças a tecnologias como a PET (positron emission tomography - tomografia por emissão de pósitrons) e FMRI (functional magnetic resonance imaging - ressonância magnética funcional) e estudos de eletrofisiologia e genética comportamental (BROOK; MANDIK, 2004). Tais instrumentos e recursos teóricos prometem revelar como o processamento de informaçóes é implementado pelo cérebro. Felizmente para seus praticantes, o campo em questão já se encontra desenvolvido o bastante para gerar teorias de fenômenos mentais diversos. Os relatos a seguir concentram-se no que a neurociência cognitiva tem a dizer sobre nossas faculdades de percepção. Mais especificamente, descrever-se-á um modelo simplificado de explicação de consciência em percepção visual. Deve ficar claro, no entanto, que existem modelos similares para fenômenos mentais diversos, tais como atos volitivos. Seja como for, modelos neurocientíficos de volição possuem o mesmo tipo de conteúdo empírico (HAGGARD, 2008).

Antes de um exame mais específico do trabalho de um neurocientista cognitivo, faz-se necessário mencionar o background teórico a guiá-lo. Em primeiro lugar, os modelos propostos são reducionistas, não somente no sentido mais óbvio, onde o que se procura é encontrar um explanans material, mas sim naquele sentido proposto pelo filósofo Jaegwon Kim:

1. Interpreta-se a propriedade a ser reduzida como uma propriedade funcional, isto é, uma propriedade definida por suas relaçóes causais.

2. São conduzidas pesquisas científicas que objetivam encontrar os mecanismos ou propriedades que realizam as ditas relaçóes causais (os seus "realizadores") na população de interesse.

3. Elabora-se uma explicação no nível mais fundamental do funcionamento dos fenômenos acima descritos. (KIM, 2005, p. 111-112).

No presente contexto, "as propriedades funcionais" devem ser compreendidas como as capacidades cognitivas como estudadas pelos cientistas cognitivos, ou seja, faculdades de processamento de informação. Por "realizadores" são tomadas estrutura fisiológicas no cérebro. Conseguintemente, 
temos a premissa fundamental: a mente deve ser identificada com determinadas atividades cerebrais. A mente está no cérebro. Nas palavras da filósofa Patricia Churchland, "[a]s evidências implicam que o cérebro, ao invés de algo nãofísico, sente, pensa e toma decisôes" (CHURCHLAND, 2002, p. 1, minha tradução). Um segundo aspecto importante do esquema em questão é a adoção de um modelo explicativo um tanto diferente daqueles onde a noção de lei natural é fundamental. Isso ocorre porque a neurociência cognitiva até agora não desvendou leis estritas instanciadas na atividade cerebral (BROOK; MANDIK, 2004, p. 386). A filosofia da ciência a sustentar a neurociência cognitiva, portanto, não é consensualmente assimilável dentro do modelo nomológico-dedutivo, ainda que busque explicaçôes via redução e previsão de novas observaçóes e especificação de dados que refutariam as teorias propostas. De qualquer maneira, trata-se de uma disciplina solidamente científica e explicativa, na medida em que prevê fenômenos de outra forma desconhecidos e se expóe à falsificaçáo. Outra premissa implicitamente presente na estrutura da neurociência cognitiva é a perspectiva da mente como um mapeamento da realidade, isto é, um sistema de representaçôes. Tal sistema é implementado pelo cérebro.

Exploremos então uma explicação no molde que acabamos de descrever. A renomada neurocientista Nancy Kanwisher, do MIT, afirma que a busca de sua disciplina por correlatos neurais da consciência tem logrado importantes êxitos, tornando possível a observação "[...] das sombras na parede da caverna da mente” (KANWISHER, 2001, p. 109, minha tradução). Através do emprego de tecnologia de imagens e (mais raramente) de registros de disparos de neurônios individuais, Kanwisher explora a possibilidade de identificação dos correlatos da consciência que são necessários e suficientes para a mesma. Uma vez encontrados, eles são identificados numericamente com o fenômeno consciente em questão - embora a questão da subjetividade mesma do fenômeno seja tipicamente deixada de lado (KANWISHER, 2001, p. 90). Para tanto, é necessário encontrar padróes de atividade neural que estáo presentes em um dado momento de consciência do conteúdo em exame, mas ausentes quando o mesmo desaparece; isso ajuda a diferenciar registros conscientes de representaçóes inconscientes (KANWISHER, 2001, p. 98-100, minha tradução). O momento em que os sujeitos de experimentos tomam consciência dos conteúdos relevantes é registrado através de comportamentos pré-determinados, como apertar um botão no momento em que um estímulo é (conscientemente) percebido. O fenômeno mental que causa o comportamento citado é chamado por Kanwisher de "senciência perceptual" 
(perceptual awareness). De posse dos conceitos citados, Kanwisher descreve um experimento onde o uso de ressonância magnética permitiu identificar a ativação da área fusiforme de faces (na sigla em inglês, FFA - fusiform face area) uma região do córtex estriado como correlato neural da percepção consciente de faces. Similarmente, a observação, no mesmo experimento, de certo padrão de ativação da área para-hipocampal de lugares (em inglês, PPA - parahipocampal place area) correlacionada à percepção consciente da foto de uma casa impeliu Kanwisher a identificar os supostos correlatos (KANWISHER, 2001, p. 91-93). Experimentos do tipo são facilmente vistos como falsificáveis (a observação dos padrôes de ativação em questão na ausência de comportamento indicando consciência, assim como a presença do segundo na ausência do primeiro, refutaria a teoria). Experimentos similares também conduziram a observações antes imprevistas: o estímulo artificial da área fusiforme com eletrodos produz experiências visuais de faces (KANWISHER, 2001, p. 96-97). Modelos neurocientíficos de voliçáo possuem características análogas (HAGGARD, 2008, p. 940, 943). Sendo assim, a neurociência cognitiva parece estar justificada em reivindicar um elevado status de rigor científico para suas teorias. O sucesso das explicaçốes propostas mostra que a redução da mente à matéria é viável.

Filósofos como David Chalmers vêm tentando barrar o caminho rumo a teorias fisicalistas da consciência, tais como o modelo de percepção descrito acima. Eles procuram demonstrar que teóricos reducionistas em geral confundem dois tipos distintos de fenômeno, o "psicológico" e o "fenomenal", e as teorias resultantes são explicaçóes apenas para o primeiro tipo (CHALMERS, 1996). Ao descartarem o "aspecto fenomenal da mente", eles cometem precisamente o erro que o filósofo Daniel Dennett atribui aos chamados "reducionistas gananciosos" (embora Chalmers não utilize o termo): ignoram algo que jamais poderia ser deixado de lado, sob pena de falsificar o fenômeno (DENNETT, 1998, p. 85-6). Vejamos o que Chalmers tem em mente, quando emprega essa distinção. $\mathrm{O}$ conceito psicológico de "mente" (CHALMERS, 1996, p. 24-31) abarca esta como uma causa ou explicação para o comportamento de um determinado organismo. Um evento mental psicológico é a instanciação de um processo cognitivo (raciocínio, representaçóes mentais de objetos, operaçôes feitas com tais representaçóes etc.). Esses processos podem ou não estar acompanhados de experiência consciente. Já o conceito fenomenal de "mente" (CHALMERS, 1996, p. 24-31) abrange unicamente experiências conscientes; eles caracterizam a mente pela maneira como sentimos nossos processos mentais. O conceito 
psicológico, ao contrário, é caracterizado apenas pelo que a mente $f a z$. Ambos os aspectos são reais, e uma boa teoria da consciência, diz Chalmers, não pode excluir nenhum dos dois. Processos mentais conscientes têm uma "vida dupla" (CHALMERS, 1996, p. 24-31); a ideia de percepção, por exemplo, pode ser entendida psicologicamente, como uma representação mental de certo objeto, ou como uma experiência subjetiva, uma sensação privada, daquilo que é representado. Eventos mentais do segundo tipo, embora não sejam redutíveis ao nível psicológico, estáo sempre associados a este (à ocorrência de um processo cognitivo).

$\mathrm{Na}$ filosofia de Chalmers, pesquisadores fisicalistas que tentam explicar a subjetividade com um modelo "mecânico" ou uma dinâmica física estão tratando de algo distinto de experiências conscientes, quer saibam ou não (CHALMERS, 1996, p. 12-13). Quem investiga a mente da primeira maneira está abordando o "Problema Fácil", e quem leva a sério a subjetividade a ponto de não querer reduzi-la a um processo físico ou funcional está tratando do "Problema Difícil". Existem, portanto, dois problemas mente-corpo. O primeiro é mais bem compreendido como um conjunto de problemas, como, por exemplo, como agem os mecanismos físicos do aprendizado, como os neurônios armazenam informação, de que forma o cérebro representa eventos etc. Todas essas questóes tratam de propriedades funcionais, instanciadas por sistemas físicos. Sendo assim, elas são problemas empíricos, que, mesmo difíceis, nada possuem de misterioso. A ciência cognitiva pode dar conta do "Problema Fácil", pois não há nenhum obstáculo metafísico a superar. O "Problema Fácil” abarca, em decorrência, questóes que, por mais interessantes que sejam, não chegam a ser mistérios - existe um programa de pesquisa razoavelmente bem definido para estudar este tipo de questão. Chalmers compara as ciências da mente com a filosofia da biologia, que lida com problemas técnicos de conceitos já bem compreendidos, como evolução, adaptação e especiação. Náo consideramos esses conceitos como mistérios metafísicos; o mesmo vale para os aspectos psicológicos, ou cognitivos, da mente.

O "Problema Difícil", por sua vez, continuaria nos incomodando, mesmo que tivéssemos uma teoria completa da mente enquanto cognição. Segundo Chalmers, podemos sempre nos perguntar como é possivel um determinado processo psicológico ser acompanhado por experiência fenomenal. Não possuímos leis para conectar o nível psicológico ao fenomenal. Além disso, não parece incoerente conceber uma criatura com processos psicológicos idênticos aos nossos, mas sem experiência subjetiva. Em outras palavras, 
uma teoria capaz de explicar nossos processos psicológicos e conectá-los ao nosso comportamento ainda teria que explicar por que esses processos são conscientes, por que nós os experimentamos. Dito de outra forma, Chalmers propóe uma investigação do "aspecto qualitativo" da nossa vida mental, nossos qualia. Para Chalmers, as ciências cognitivas não fizeram progresso nenhum nesse sentido e nem poderiam, já que tratam de uma questão diferente.

Discussōes filosóficas sobre a consistência e uso do termo qualia já duram décadas. Mesmo reconhecendo a engenhosidade da crítica de Chalmers e demais filósofos antirreducionistas à empreitada neurocientífica, vale perguntar se o uso do conceito tem ajudado de alguma maneira a filosofia a explicar os dados. Os qualia subjetivos descritos acima acompanham os processos mentais objetivamente (no sentido de acesso de terceira pessoa) cognoscíveis, mas não parecem ter um papel causal em qualquer fenômeno natural. Sendo a atividade explicativa em parte a busca de nexos de fenômenos unidos por relaçôes de determinação/causação, a aparente redundância da mente fenomenal a torna um candidato fraco a termo teórico em explicaçóes e leis. De fato, é essa característica dos qualia que fez emergir a versão contemporânea do problema da causação mental. Filósofos cuja posição antirreducionista advém de seu compromisso com a realidade dos qualia há muito tentam exorcizar o espectro da irrelevância causal dos mesmos. Dado que a eficácia causal de nossa vida mental é o que parece torná-la um objeto interessante de estudo, a filosofia da consciência centrada em qualia parece pouco atraente. Sendo assim, convém à filosofia explorar novas alternativas. Em outras palavras, interessa aos filósofos da mente abordar as aparentes falhas da perspectiva neurocientífica sob novos pontos de vista. É lícito perguntar também se os estudiosos em questáo possuem ferramentas de caráter distintamente filosófico para uma contribuição teórica positiva. É preciso examinar o papel da filosofia da mente como atividade explicativa.

Existem, por conseguinte, novas ideias filosóficas que contestam as ideias da ortodoxia neurocientífica, ao mesmo tempo em que apontam evidências sólidas de um caminho mais promissor? Os filósofos Tyler Burge e Alva Noë pensam que sim. No que se segue, examinaremos primeiro as ideias de Burge e, em seguida, as de Noë. Ao fazê-lo, devemos notar um aspecto de continuidade com o modelo exemplificado pelo trabalho de Kanwisher, a saber, o foco na percepção visual como ilustrando o funcionamento da mente como um todo.

Podemos introduzir a crítica de Burge às ambições neurocientíficas com sua defesa da ciência cognitiva da visão como disciplina matematicamente 
rigorosa e preditiva. Segundo Burge, na medida em que é uma ciência da representação, a ciência cognitiva da visão é explanatoriamente mais satisfatória do que a neurociência cognitiva. Não obstante sua utilização do termo, a neurociência cognitiva não é uma ciência da representação, porque seu foco em cérebros deixa de lado a interação com o ambiente e a forma como a mesma moldou nosso aparato mental.

Qual o diferencial de uma ciência da representação mental? Burge expóe suas ideias destacando o uso especificamente psicológico do termo "representação". O emprego distintamente psicológico pode ser compreendido em contraste com uma noção mais genérica, em que "representação" aponta para uma função de correlação. A noção genérica é adotada em contextos biológicos, quando se diz, por exemplo, que uma bactéria ajusta sua posição através de uma "representação" da luz. O que a bactéria faz é registrar informaçôes, da mesma forma que uma planta é capaz de correlacionar sua posição com a direção da luz (BURGE, 2010a, p. 494). Trata-se de identificar conexôes sistemáticas entre propriedades dos seres vivos e características de seus habitats. A abordagem distintamente psicológica é mais sofisticada. Voltemo-nos para o que revela a psicologia da percepção: representaçôes que sustentam estados perceptuais são marcadas por graus de exatidâo. Para satisfazer a definiçãa proposta por Burge, estados mentais têm de possuir conteúdo que atribui propriedades físicas ao mundo de forma razoavelmente confiável, ou seja, de forma mais ou menos verossímil. Em outras palavras, temos “[...] estados perceptuais com conteúdo representacional que aponta para entes específicos no ambiente físico" (BURGE, 2010a, p. 342, minha tradução). Assumindo a necessidade de graus de exatidão, torna-se possível explicar as constâncias perceptuais (perceptual constancies) que caracterizam capacidades perceptuais. Constâncias perceptuais são aptidóes que permitem a percepçáo de uma propriedade do ambiente como sendo a mesma, não obstante o "ruído" e as flutuaçôes do estímulo.

A psicologia da percepção está apta a explicar a formação de nossos estados perceptuais, porque investiga os processos que tornam possível as constâncias perceptuais, e, consequentemente, a relativa exatidão da percepçáo. Eras de interação com o ambiente deram origem à evolução de "hipóteses" que organismos utilizam para orientar a computação dos inputs ambientais. A necessidade desses recursos fica clara quando consideramos a questão a seguir. Sistemas visuais notoriamente confrontam o problema da subdeterminação. Um exemplo do problema: sabe-se que o registro da luz que impacta a retina não é suficiente por si só para determinar a localização e a distância do estímulo 
causador. Para atribuir uma localização correta ao estímulo, o sistema visual lança mão da geometria de visáo binocular. Note-se primeiro que os dois olhos convergem para um dado ponto no espaço. $\mathrm{O}$ ângulo formado pelas duas linhas de visão está sistematicamente correlacionado à distância entre o observador e o ponto visado. Um objeto próximo, quando visado, gera um ângulo maior, que diminui, na medida em que ele se afasta. O outro ângulo relevante é formado pela interseção da linha entre o ponto de fixação e um ponto entre os dois olhos e a linha que se projeta diretamente dos olhos. Assumindo a hipótese de que a distância entre os olhos é sempre a mesma, e que os ângulos acima descritos podem ser averiguados pelo sistema, é possível computar localização e distância através de princípios geométricos. Burge observa que esse processo de engenharia reversa foi confirmado experimentalmente como a solução encontrada pelo sistema visual humano para o cálculo de distância e localização de objetos (BURGE, 2010a, p. 342-348).

A faculdade mental que acaba de ser descrita, chamada convergência, é uma das constâncias perceptuais mencionadas anteriormente. A atribuição de localização e distância por convergência é eficaz independentemente de variáveis como forma, textura ou cor dos objetos. Dito de outra maneira, temos constância perceptual, porque estímulos de tipos variados têm o mesmo tipo de efeito sobre o sistema. O processo que explica a constância perceptual em questão evoca um processo assemelhado a uma lei natural (law-like process). Tendo revelado tal processo de maneira rigorosamente científica, a ciência da visão - um ramo da psicologia perceptual - exibe caráter genuinamente explicativo. As consideraçóes sobre o ângulo formado pela visada de um objeto distante relacionam o ambiente ao organismo e fundamentam o emprego da noção rigorosa de representação. Algo similar ocorre, quando consideramos outras constâncias perceptuais, como a atribuição de luminosidade a uma superfície e a detecção de profundidade a partir de convexidade. Em ambos os casos, informaçóes estatisticamente relevantes sobre o ambiente são assumidas nas operaçóes geradoras de percepção (BURGE, 2010a , p. 351, 361).

Burge argumenta que tais resultados ilustram uma compreensão da percepção visual muito mais profunda do que modelos como o de Kanwisher. A menção de correlatos neurais da consciência não ilumina o processo que conduz à elaboração de representações razoavelmente fiéis do mundo externo. Os problemas que organismos vivos precisam resolver para prosperar em seus respectivos ambientes, assim como as soluçóes "encontradas" pela seleção natural, permanecem indistintos quando focamos apenas o cérebro em ação. 
A ciência que torna salientes os fundamentos da representação possui caráter "distintamente psicológico" (BURGE, 2010a, p. 342, minha tradução). A perspectiva neurocientífica é "puramente descritiva" e, isoladamente, "nada explica” (BURGE, 2010b, p. 2, minha tradução).

Não é de todo surpreendente constatar que a filosofia de Burge contesta a alegação neurocientífica de que a mente está no cérebro. $\mathrm{O}$ design para o qual Burge chama atenção, afinal, é o design do organismo, e não uma exploração de um de seus aspectos fisiológicos. De acordo com Burge, percepçóes são atribuíveis a indivíduos, e não a cérebros. Estados perceptuais são recursoschave para as açôes de organismos complexos. Tais ações são comumente explicadas por um apelo a percepçóes; segue-se que as mesmas devem ser atribuídas ao indivíduo, pois mobilizam o mesmo como um todo. Recursos sensoriais só são atribuíveis a partes do organismo, em separado, quando as mesmas podem operar como um indivíduo independente. Isso é o que ocorre, por exemplo, com as pequenas pinças (pedicelárias) de ouriços. Pedicelárias são sensíveis a contato e podem responder a estímulos, quando removidas do animal (BURGE, 2010a, p. 373). Cérebros, porém, não exibem atividade independentemente do resto do corpo. Além disso, percepçóes são sempre estados de algo que possui uma perspectiva. Indivíduos possuem perspectivas; cérebros, não. Conclui-se que cérebros não são capazes de perceber o que quer que seja (BURGE, 2010a, p. 373). Burge considera seus insights sobre percepção válidos para as demais faculdades mentais. A partir dessa generalização, ele conclui que é absurdo afirmar, como Churchland, que o cérebro pensa e toma decisões (BURGE, 2010b).

A filosofia de Alva Noë compartilha uma desconfiança análoga em relaçáo ao poder explicativo da neurociência cognitiva. Noë concorda com Burge a respeito da necessidade de explicaçóes de caráter holístico, em que as teorias da percepção levam em conta o ambiente onde o organismo está inserido. Com efeito, Noë pensa ser absurda a pretensão da neurociência de identificar a mente com um conjunto de processos cerebrais; isso implica a extravagante possibilidade de consciência em uma placa de Petri (NOË, 2010, p. 12). Só podemos explicar a consciência em um contexto de ação inserida na realidade biológica do indivíduo.

As objeçôes de Noë ao projeto neurocientífico ortodoxo contestam a completude das observaçóes feitas com ressonância magnética, tomografia computadorizada e recursos afins. Noë afirma que tais tecnologias são muito mais limitadas do que fazem crer certos relatos neurocientíficos. O emprego de 
imagens do cérebro não torna a observação da atividade cerebral uma simples questão de examiná-las e apreender diretamente o que se passou. Em primeiro lugar, é problemático definir um limiar para o início das atividades visadas pela teorização. Esse é o caso, porque o cérebro nunca está em repouso e a comparação da atividade cerebral antes e depois do limiar definido assume que não existem "mecanismos de retroalimentação" (feedback mechanisms) a acionar as estruturas ativadas inicialmente com informação processada mais adiante. Dado que de fato existem mecanismos do tipo (KOCH, 2001, p. 120-121), a tarefa de observar eventos mentais com o auxílio das novas tecnologias torna-se muito mais complicada. Pensemos na comparação da atividade cerebral antes e depois do fenômeno-alvo, através das respectivas imagens produzidas em um aparelho de ressonância: se existe retroalimentação, é perfeitamente possível que a atividade neural correlacionada a um estágio anterior de processamento seja confundida com aquela correlacionada ao fenômeno-alvo. Noë ilustra tal cenário evocando casos nos quais expectativas (processamento posterior, relacionado à atenção) influenciam a percepção de estímulos (o fenômeno anterior). Esse é o caso quando nosso conhecimento facilita a discriminação de palavras de uma língua estrangeira - o leitor provavelmente pode recordar o contato com uma língua diferente da sua, a ponto de ser difícil distinguir sons e palavras específicos (NOË, 2010, p. 22).

Uma segunda objeção contra a identificação de fenômenos mentais com correlatos neurais diz respeito à plasticidade cerebral. A ideia de que a mente é um sistema de módulos para processamento de informação prevê a existência de sistemas especializados para cada modalidade sensorial, e é tornada plausível por dados como os experimentos supracitados envolvendo a área fusiforme para faces. Como vimos, Kanwisher correlaciona e identifica a atividade nessa estrutura com a percepção de faces. A FFA seria então um módulo para a percepção de um tipo específico de objeto, assim como a área para-hipocampal de lugares é um módulo para detecção perceptual de lugares. Noë argumenta que conclusóes do tipo são precipitadas. Esse é o caso não somente porque a possibilidade de observar diretamente os eventos visados é duvidosa, mas também porque o cérebro é capaz de recrutar áreas associadas a uma dada modalidade sensorial para funçôes diferentes. Em seu livro Out of our heads, Noë menciona experimentos com furóes, em que os olhos dos animaizinhos são conectados a regióes cerebrais normalmente associadas à audição (NOË, 2010, p. 53-56). Se houvesse alguma propriedade do córtex visual a caracterizar experiências como percepçóes visuais, e outra propriedade do córtex auditivo caracterizando experiências como auditivas, os furóes 
“ouviriam com seus olhos”. A área ativada pelo input dos olhos, afinal, é o suposto módulo projetado para a representação de sons. Mas não é isso o que ocorre. Os furōes não ficam cegos, e suas percepções envolvem a ativação de suas estruturas cerebrais "auditivas". Portanto, é enganoso identificar este ou aquele fenômeno mental com esta ou aquela estrutura cerebral. A estrutura "auditiva" não é o fator-chave aqui: o que explica seu papel na experiência é sua conexão com uma determinada fonte de informação.

Se o caráter das experiências perceptuais depende de como os inputs chegam ao organismo, existe uma boa razáo para explorar uma hipótese na qual a interação com o ambiente é um fator explicativo fundamental. O leitor terá percebido aqui um importante ponto em comum com a abordagem de Burge. No entanto, a contribuição positiva de Noë - sua teoria da percepção, generalizada para as demais atividades da mente - é bastante diferente. Muito resumidamente, Noë (2010, p. 47-65) afirma que experiências perceptuais ocorrem quando organismos empregam seu domínio das leis de contingências sensoriomotoras . Dito de outra maneira, organismos conscientes possuem subjetividade em virtude do uso de habilidades especiais que envolvem um tipo de conhecimento não-proposicional. Tais organismos sabem explorar certos potenciais de obtenção de informação de seus ambientes. Criaturas capazes de ver, por exemplo, têm domínio da relação nomológica entre suas ações e estímulos visuais. Essa relação é determinada pela constituição de seus aparatos visuais. Nas palavras de Noë (2010, p. 60, minha tradução), “[...] a aparência das coisas depende, de maneiras sutis e detalhadas, do que você faz. Aproxime-se de um objeto e ele cresce no seu campo visual. Agora dê as costas para ele: o objeto desaparece do seu campo de visão". Animais conscientes compreendem tacitamente as contingências sensoriomotoras determinadas por objetos visíveis e atributos como cores, forma e tamanho. O caráter visual de uma forma, por exemplo, é o conjunto de todas as distorçốes potenciais que ocorrem quando um dado objeto é movido relativamente ao sujeito, e vice-versa. Similarmente, a sensação de cor é determinada pela forma como uma superfície interage com a luz, quando movida relativamente ao sujeito ou fontes luminosas. A estrutura dessa dinâmica é regida por leis, e a integração das atividades que dependem de conhecimento das leis relevantes no planejamento de ações, em operaçóes de raciocínio e no discurso, é experimentar cores. As demais modalidades sensoriais são caracterizadas por conjuntos de leis próprias. Consideremos contingências sensoriomotoras auditivas: movimentos oculares ou um piscar de olhos em nada interferem nesse contexto, ao contrário de rotaçóes da cabeça. Quando movemos nossas cabeças na direção de uma fonte 
sonora, a amplitude do estímulo é modificada (NOË; O’REGAN, 2001, p. 941). De forma análoga, informaçóes táteis não provêm de um ponto de vista, nem dependem de fontes de luz. As transformaçóes relevantes dependem de contato com objetos, ou seja, de um uso particular de nossos corpos. O tato permite a percepção da forma de objeto, quando compreendemos que movimentos são "[...] permitidos pelos contornos de um objeto" (NOË, 2010, p. 61, minha tradução).

Qual é, então, o papel do cérebro na filosofia da mente de Noë? O cérebro é um elemento fundamental para a consciência porque ele "coordena nossas interaçóes com o ambiente" (NOË, 2010, p. 65, minha tradução). $\mathrm{Na}$ ausência de um ambiente possibilitando tais interaçôes, porém, não existe experiência. A percepção é análoga a uma dança em dupla; quando dançamos, movemo-nos desta ou daquela maneira porque nosso parceiro executou um dado movimento. Cérebros estáo similarmente conectados ao ambiente. Isso implica a falsidade de uma perspectiva neurocientífica na qual atividades representacionais no cérebro bastam para gerar experiências. De fato, “[...] o mundo que nos rodeia é aquilo que determina a natureza da experiência consciente" (NOË, 2010, p. 142, minha tradução).

A breve exposição das ideias de Burge e Noë mostra que a filosofia da consciência não depende unicamente de experimentos de pensamento e noçóes como qualia. É possível utilizar a filosofia para ir além das ideias sobre a conceptibilidade de uma consciência irredutível. Os filósofos em questão propóem conceitos inovadores sobre o funcionamento e a natureza da mente. Abre-se, portanto, um promissor campo de investigação na fronteira entre a filosofia da mente e filosofia da ciência. Devemos nos perguntar, em primeiro lugar, se as alternativas de Burge e Noë são mais consistentes, nos termos da filosofia da ciência. Outra questão intrigante é a possibilidade de absorção de alguns dos seus insights pela neurociência ortodoxa. Poderia a mesma mostrar que a ciência da visão é uma forma mais abstrata de descrever o fenômeno do cérebro? Podem os neurocientistas integrar a importância de contingências sensoriomotoras em seu esquema computacional e representacional? As atuais controvérsias permitem prever debates ricos em oportunidades para os filósofos da mente. 
HOLLANDA, Gabriel Jucá de. New directions in the philosophy of mind. Trans/Form/ Ação, Marília, v. 36, n. 3, p. 173-186, Set./Dez., 2013.

\begin{abstract}
Critiques of naturalist/physicalist theories in the philosophy of mind have focused on conceptual problems rooted in qualia and thought experiments. It would seem reasonable to question the validity of such critiques when their targets satisfy what is demanded of a scientific explanation and when their objections employ apparently ad hoc assumptions. The philosophers of mind Tyler Burge and Alva Noë propose new ways of objecting to contemporary neuroscience, without making use of the usual conceptual tools. Their viewpoints stand out for a focus on empirical problems, and at the same time reveal surprising gaps in what physicalists tend to see as the most advanced science of the mind.
\end{abstract}

KEY WORDS: Mind. Neuroscience. Perception. Vision. Explanation.

\title{
REFERÊNCIAS
}

BROOK, Andrew; MANDIK, Pete. The philosophy and neuroscience movement. Analyse \& Kritik, n.26, p. 382-397, 2004.

BURGE, Tyler. Origins of objectivity. Nova York: Oxford University Press, 2010a.

. A real science of the mind. Disponível em: http://opinionator.blogs.nytimes. com/2010/12/19/a-real-science-of-mind. Acesso em: 20 nov. 2010.

CHALMERS, David J. The conscious mind: in search of a fundamental theory. Nova York: Oxford University Press, 1996.

CHURCHLAND, Patricia S. Brain-wise: Studies in neurophilosophy. Cambridge, MA: The MIT Press, 2002.

DENNETT, Daniel. C. A perigosa ideia de Darwin. Tradução de Talita M. Rodrigues. Sáo Paulo: Rocco, 1998.

DRIVER, John; VUILLEUMIER, Patrik. Perceptual awareness and its loss in unilateral neglect and extinction. In: DEHAENE, Stanislas (Org.). The cognitive neuroscience of consciousness. Cambridge, MA: The MIT Press, 2001, p. 39-88.

GODFREY-SMITH, Peter. Theory and reality: an introduction to the philosophy of science. Chicago: The University of Chicago Press, 2003.

HAGGARD, Patrick. Human volition: towards a neuroscience of will. Nature Reviews Neuroscience, v. 9, n.12, p. 934-946, 2008.

KANWISHER, Nancy. Neural events and perceptual awareness. DEHAENE, Stanislas (Org.). The cognitive neuroscience of consciousness. Cambridge, MA: The MIT Press, 2001, p. 89-113. 
KIM, Jaegwon. Physicalism, or something near enough. Princeton: Princeton University Press, 2005.

KITCHER, Philip. Explanatory unification. Philosophy of Science, v. 48, n. 4, p. 507-531, 1981.

$\mathrm{KOCH}$, Cristof. The quest for consciousness: a neurobiological approach. Englewood: CO, Roberts and Company Publishers, 2001.

LAKATOS, Imre. Science and pseudoscience. Disponível em: http://www2.lse.ac.uk/ philosophy/about/lakatos/scienceandpseudosciencetranscript.aspx. Acesso em: 20 set. 2010.

NOË, Alva. Out of our heads: why you are not your brain, and other lessons from the biology of consciousness. Nova York: Hill and Wang, 2010.

O'REGAN, Kevin; NOË, Alva. A sensorimotor account of vision and visual consciousness. Behavioral and Brain Sciences, v. 24, n.5, p. 939-1031, 2001.

Recebido em: 07.08.2012

Aceito em: 23.03.2013 